\title{
Using electrical signals of microbial fuel cells to detect copper stress on soil microorganisms
}

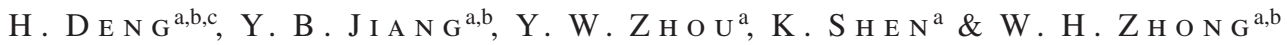 \\ ${ }^{a}$ Department of Environmental Science and Engineering, School of Geography Science, Nanjing Normal University, No.1 Wenyuan Road, \\ 210023, Nanjing, China, bJiangsu Provincial Key Laboratory of Materials Cycling and Pollution Control, No.1 Wenyuan Road, 210023, \\ Nanjing, China, and ${ }^{\mathrm{c}}$ Research Center for Eco-Environmental Sciences, Chinese Academy of Sciences, No.18 Shuangqing Road, 100085, \\ Beijing, China
}

\begin{abstract}
Summary
A method based on microbial fuel cells (MFCs) was used to evaluate the effects of copper $\left(\mathrm{Cu}^{2+}\right)$ on soil microorganisms. Soil spiked with $50-400 \mathrm{mg} \mathrm{kg}^{-1}$ of $\mathrm{Cu}^{2+}$ as $\mathrm{CuCl}_{2}$ was incubated for 24 hours before being packed into the MFC anode chambers and assayed for dehydrogenase activity (DHA), substrate-induced respiration (SIR) and microbial biomass carbon $\left(\mathrm{C}_{\text {mic }}\right)$. Soil was amended with $5 \%(w / w)$ glucose to accelerate 'start-up' and improve power generation, followed by 150 hours of operation. Anode biofilm and soil was extracted to recover total nucleic acids and the 16S rRNA gene was subjected to PCR-DGGE, sequencing and phylogenetic analysis. Results showed that increases in soil $\mathrm{Cu}^{2+}$ concentrations reduced voltage and postponed start-up. The quantity of generated electrons within 48 hours was 32.5 coulomb $(\mathrm{C})$ in the without-Cu control and decreased with increasing $\mathrm{Cu}^{2+}$ concentrations (11.7, 7.7, 2.0 and 1.3 $\mathrm{C}$ under 50, 100, 200 and $400 \mathrm{mg} \mathrm{kg}^{-1} \mathrm{Cu}^{2+}$, respectively). Cyclic voltammetry identified decreased soil electrochemical activity with increasing $\mathrm{Cu}^{2+}$ concentrations. The results indicate that $\mathrm{Cu}^{2+}$ reduced electrical signals by inhibiting the electrochemical activity, metabolic activity and biomass of microorganisms. The 16S sequences of recovered anodic bacteria were assigned to Firmicutes, including Bacillaceae, Acetobacteraceae, Clostridium, Bacillus and Sporolactobacillus. In general, the DGGE band intensity of anodic bacteria decreased with increasing $\mathrm{Cu}^{2+}$ concentrations, except for bands assigned to Firmicutes and Bacillus, which increased with increasing $\mathrm{Cu}^{2+}$ concentrations. We suggest that the short-term electrical signals generated from MFCs with contaminated soil can be used to assess the toxic effect of heavy metal pollutants on soil microorganisms.
\end{abstract}

\section{Introduction}

A microbial fuel cell (MFC) is a device that converts chemical energy from organic compounds into electricity by using electrogenic bacteria as biocatalysts (Bond \& Lovley, 2003). A dual chamber MFC usually consists of an anode chamber and a cathode chamber separated by a proton exchange membrane. In the anode chamber, electrogenic bacteria degrade organic compounds and transfer electrons to the anode. The electrons then flow through a conductor to the cathode, where they bind with an acceptor such as oxygen or ferricyanide and thus current is generated. Because the current is closely correlated with the metabolic activity of electrogenic bacteria, MFC-based biosensors have been developed to monitor the biological oxygen demand in wastewater (Di Lorenzo et al., 2009), heavy metal toxicity (Stein et al., 2010, 2011) and acid toxicity (Shen et al., 2012). In MFC-based biosensors, a

Correspondence: W. H. Zhong. E-mail: zhongwenhui@njnu.edu.cn

Received 21 December 2013; revised version accepted 29 September 2014 culture of mixed electrogenic bacteria from other active MFCs (Stein et al., 2010) or a pure culture of Geobacter or Shewanella have been used to generate a current with growth medium in the anode chamber (Dávila et al., 2010). During the sensing process, wastewater or chemicals were added to the anode chamber after electrogenic bacteria enriched on anode and generated stable current (Shen et al., 2013). The current decreased with increasing pollutant toxicity and increased with increasing BOD concentrations (Kim et al., 2008).

It is known that soil can be used to generate electrical power in MFCs and a diversity of electrogenic bacteria have been detected. Ringelberg et al. (2011) found that a variety of soils had electrogenic activity and bacteria belonging to $\alpha$ - and $\beta$ Proteobacteria and Firmicutes dominated anodic biofilms in soilbased bio-electrochemical systems. Ishii et al. (2008) found that Clostridiales, Chloroflexi, Rhizobiales and Methanobacterium dominated the anode biofilm in MFCs inoculated with soil from a rice field. Kaku et al. (2008) operated plant-MFCs in which soil 
organic carbon and rice exudates served as energy resources, and found that Natronocella acetinitrilica, Beijerinckiaceae bacterium and Rhizobiales bacterium were dominant on the anode. In recent studies, more than 30 isolates belonging to Firmicutes and $\alpha$-, $\beta$-, $\gamma$ - and $\delta$-Proteobacteria were verified as electrogenic bacteria (da Rosa, 2011) and many more microorganisms detected on the anode by molecular methods were thought to have electrogenic activity. As electrogenic bacteria are widely distributed in soils and soil bacteria are sensitive to environmental changes, stress on soil microbial communities may inhibit electrogenic activity. For example, Deng et al. (2014) found that the voltage generated by a soil varied synchronously with incubation temperature. We hypothesize that the electrical signals produced by electrogenic bacteria in soil can be used to assess heavy metal toxicity in soil.

In the present study, we used soil with different amounts of $\mathrm{Cu}^{2+}$ added and subjected it to a series of measurements that included glucose dehydrogenase activity (DHA), substrate-induced respiration (SIR), microbial biomass carbon $\left(\mathrm{C}_{\text {mic }}\right)$ and the electrical signals of MFCs, including voltage and the quantity of electrons. The DHA, SIR and $\mathrm{C}_{\text {mic }}$ characteristics are sensitive to environmental changes and are conventional bioindicators of soil pollution (Wang et al., 2007). In our study the monitoring process is different from that for wastewater. The pure culture electrogenic bacteria and medium are unnecessary. They increase cost and the medium, if it were to be discharged, may lead to pollution. Instead, we used the endogenous soil electrogenic bacteria and, because soil usually contains adequate nutrients, we only amended soil with glucose to minimize the 'start-up' time for power generation and to improve the voltage output (Kim et al., 2000). A regression analysis was conducted to compare responses between the electrical signals, DHA, SIR and $\mathrm{C}_{\text {mic }}$ to $\mathrm{Cu}^{2+}$ toxicity. The effect of $\mathrm{Cu}^{2+}$ exposure on microbial community structure on the anode and in the soil was assessed by using DGGE, sequencing and phylogenetic analysis based on the 16S rRNA gene. The intent of this study was to develop a MFC-based method to detect heavy metal toxicity in soil microorganisms.

\section{Materials and methods}

\section{Soil sampling and chemical analysis}

Soil samples were collected in October 2012 at a depth of 0-20 cm from a broad-leaf forest at Nanjing Normal University, Nanjing City, China. The climate is sub-tropical and wet with an average annual precipitation of $1100 \mathrm{~mm}$ and a mean annual temperature of $15^{\circ} \mathrm{C}$. After sampling, the soil was gently separated by hand to preserve soil structure, passed through a 2-mm mesh and thoroughly mixed. Part of the sieved soil was air-dried for physiochemical analysis. Soil texture was determined with the pipette method (Gee \& Bauder, 1986). Total carbon and total nitrogen were measured with an elemental analyser (Vario EL III, Elementar, Hanau, Germany). Soil $\mathrm{pH}$ was measured at a soil:water ratio of 1:2.5 (w/v). Total $\mathrm{Cu}$ and total iron $(\mathrm{Fe})$ in soil were determined using inductively coupled plasma (Prodigy, Leeman Labs Inc., Hudson, NY, USA). Soil electrical conductibility (EC) was determined with an electrical conductibility meter (DDSJ-308F, INESA Scientific Instrument Co.,
Ltd, Shanghai, China). The soil is categorized as an Alfisol (IUSS Working Group WRB, 2007). The soil physiochemical properties were as follows: soil texture, clay loam; total carbon, $18.1 \mathrm{mg} \mathrm{g}^{-1}$; total nitrogen, $0.62 \mathrm{mg} \mathrm{g}^{-1}$; soil $\mathrm{pH}, 7.57$; total $\mathrm{Cu}, 41.1 \mu \mathrm{g} \mathrm{g}^{-1}$; total $\mathrm{Fe}, 29.4 \mathrm{mg} \mathrm{g}^{-1}$; EC, $76.6 \mu \mathrm{S} \mathrm{cm}^{-1}$.

\section{Copper stress experiment}

The soil was divided into five aliquots, each with $600 \mathrm{~g}$ soil (dry mass). Thirty millilitres of $\mathrm{CuCl}_{2}$ solution was added to each aliquot to yield 50,100, 200 and $400 \mathrm{mg} \mathrm{Cu}^{2+} \mathrm{kg}^{-1}$ dry mass soil at a final soil moisture content of $18 \%$. The remaining aliquot received $30 \mathrm{ml}$ distilled water to serve as a control. The soil of each aliquot $(600 \mathrm{~g})$ was placed into a vial (1 litre) and incubated in the dark at $26^{\circ} \mathrm{C}$ for 24 hours. To help maintain the moisture content, a lid was placed loosely on each vial. After incubation, each soil aliquot was thoroughly mixed and equally divided into three sub-aliquots ( $200 \mathrm{~g}$ for each) as three replicates before the measurements of electrical signals, $\mathrm{SIR}$, DHA and $\mathrm{C}_{\text {mic }}$.

\section{MFC set up}

Fifteen dual chamber MFC reactors were constructed in oroglas ${ }^{\circledR}$. An MFC reactor consisted of an anode chamber and a cathode chamber (each chamber with a dimension of $6 \times 6 \times 6 \mathrm{~cm}^{3}$ and a working volume of $170 \mathrm{ml}$ ) separated by a Nafion ${ }^{\circledR}$ cation exchange membrane (Figure 1). The anode and cathode were made of carbon felt with the same area of $16 \mathrm{~cm}^{2}\left(4 \times 4 \mathrm{~cm}^{2}\right)$, fixed in parallel and separated by the cation exchange membrane. The distance between electrodes was $6 \mathrm{~cm}$. The cathode chambers of the $15 \mathrm{MFC}$ reactors were filled with $50 \mathrm{~mm}$ potassium ferricyanide (in $50 \mathrm{~mm}$ phosphate buffer solution (PBS)). The 15 reactors were randomly divided into five groups (three MFCs per group) according to $\mathrm{Cu}^{2+}$ concentration (control, 50, 100, 200 and $400 \mathrm{mg} \mathrm{kg}^{-1}$ ). One hundred and fifty grams (dry mass) of contaminated or control soil was amended with $5 \%(w / w)$ glucose and packed into one anode chamber. Distilled water was added to the anode chamber to keep soil saturated. The anode and cathode were connected to a $1000 \Omega$ external load by titanium wire. The $15 \mathrm{MFCs}$ were operated at $26^{\circ} \mathrm{C}$ in a constant temperature incubator. The voltage was recorded with a data acquisition module every 10 minutes for 150 hours. To determine whether power originated from the microbial process or chemical processes, the voltage of an MFC reactor with uncontaminated soil sterilized by the chloroform fumigation method (Wolf et al., 1989) was recorded.

\section{Electrochemical activity}

The electrochemical activity of soil from the anode chambers was examined by cyclic voltammetry (CV) following 150 hours of operation. Briefly, $50 \mathrm{~g}$ of $\mathrm{Cu}^{2+}$-spiked soil from the MFC anode chamber and soil sterilized by $\mathrm{CHCl}_{3}$ fumigation were collected and centrifuged at $1400 \mathrm{~g}$ for 10 minutes. The extracted soil solution was filtered through $0.45-\mu \mathrm{m}$ pore size membrane and aerated with nitrogen gas for 10 minutes. Cyclic voltammetry 


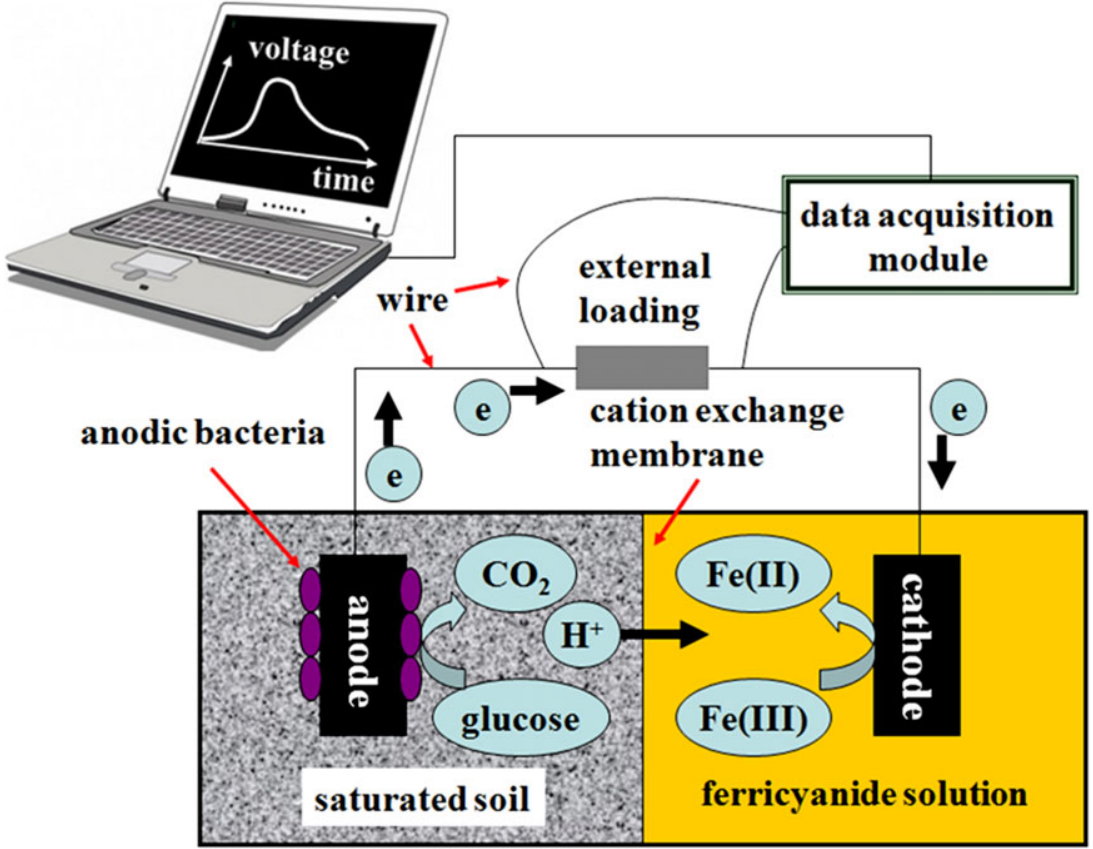

Figure 1 Diagram of MFC to detect $\mathrm{Cu}^{2+}$ stress on soil microorganisms. The anodic bacteria from soil degrade carbon substrate to produce electrons and protons. The electrons are transmitted to the cathode trough the wire and reduce $\mathrm{Fe}$ (III) to $\mathrm{Fe}$ (II) in the cathode chamber. The produced voltage is recorded with a data acquisition module. measurement of the extracted soil solution was conducted with a potentiostat (CHI 1040 C, Shanghai Chenhua, Shanghai, China) with a three-electrode configuration consisting of the working electrode (glasses carbon), a counter electrode (platinum wire) and an $\mathrm{Ag} / \mathrm{AgCl}$ reference electrode. The scanned potential between -1 and $+1 \mathrm{~V}$ (against standard hydrogen electrode (SHE)) was performed at a scan rate of $50 \mathrm{mV} \mathrm{s}^{-1}$ under quiescent conditions with a working volume of $5 \mathrm{ml}$.

\section{DHA, SIR and $C_{\text {mic }}$}

Values of DHA were determined according to Casida et al. (1964). Briefly, $1 \mathrm{~g}$ soil (dry mass equivalent) was combined with $2 \mathrm{ml}$ $1 \%(w / v)$ 2, 3, 5-triphenyltetrazolium chloride (TTC) as a substrate. The triphenylformazane (TPF) produced was determined by spectrophotometry at $485 \mathrm{~nm}$. Measurement of SIR was according to Lipson et al. (1999). Glucose was added to $10 \mathrm{~g}$ of soil (dry mass equivalent) in a $250-\mathrm{ml}$ vial to give a final concentration of $30 \mathrm{mg} \mathrm{g}^{-1}$ dry soil. The vials were sealed and incubated for 12 hours at a constant $26^{\circ} \mathrm{C}$. The $\mathrm{CO}_{2}$ was trapped in $0.2 \mathrm{M} \mathrm{NaOH}$ solution in a $15-\mathrm{ml}$ flask placed inside the $250-\mathrm{ml}$ vial and determined by titration with $0.05 \mathrm{M} \mathrm{HCl}$ following the addition of $1 \mathrm{M} \mathrm{BaCl}_{2}$. $\mathrm{C}_{\text {mic }}$ was determined using the protocol described by Vance $e t$ al. (1987). Ten grams of soil (dry mass equivalent) were fumigated with ethanol-free $\mathrm{CHCl}_{3}$ and extracted in $0.5 \mathrm{M} \mathrm{K}_{2} \mathrm{SO}_{4}$. The organic carbon in the soil extract was measured with an automated TOC analyser (TOC-VCSN, Shimadzu, Kyoto, Japan).

\section{DNA extraction and PCR}

After the 150 -hour operation of MFCs, a piece $\left(1.5 \times 1.5 \mathrm{~cm}^{2}\right)$ of the anode and $0.5 \mathrm{~g}$ of soil from the anode chamber were collected.
The anode was rinsed with sterilized deionized water to remove soil before DNA extraction (He et al., 2009). The genomic DNA of the collected anode and soil was immediately extracted by using the Fast DNA SPIN kit for soil (BIO101, MP Biomedicals, Carlsbad, CA, USA) and following the manufacturer's instructions. The purity and the quantity of the DNA were determined by a nanodrop ND-1000 UV-Vis spectrophotometer (NanoDrop Technologies, Wilmington, DE, USA) at 230, 260 and $280 \mathrm{~nm}$.

The bacterial 16S rRNA gene was amplified with the primer set $341 \mathrm{f}\left(5^{\prime}\right.$-CCT ACG GGA GGC AGC AG-3') with a 40-bp GC clamp (5'-CGC CCG CCG CGC CCC GCG CCC GGC CCG CCG CCC CCG CCC C-3') and 907r (5'-CCG TCA ATT CMT TTG AGT TT- $3^{\prime}$ ) (Muyzer et al., 1993). The 50- $\mu 1$ reaction mixtures contained $1 \mu \mathrm{l}$ template DNA, $1 \mu \mathrm{l}$ of each $1 \mu \mathrm{M}$ primer, $5 \mu \mathrm{l} 10 \times$ buffer ( $\mathrm{Mg}^{2+}$ plus), $4 \mu 110 \mathrm{~mm}$ dNTPs mixture (2.5 mM of each) and 2.5 units of Taq DNA polymerase (Sangon Biotech, Shanghai, China). Thermal cycling conditions were as follows: initial denaturation at $94^{\circ} \mathrm{C}$ for 4 minutes; 35 cycles consisting of denaturation at $94^{\circ} \mathrm{C}$ for 1 minute, primer annealing at $54^{\circ} \mathrm{C}$ for $30 \mathrm{~s}$, and elongation at $72^{\circ} \mathrm{C}$ for $30 \mathrm{~s}$.

\section{DGGE, sequencing and phylogenetic analysis}

The DGGE was performed with $8 \%$ polyacrylamide gel with a denaturing gradient of $40-80 \%$ (100\% denaturant $=7 \mathrm{~m}$ urea, $40 \%(v / v)$ formamide) using the Bio-Rad Protean II System for 15 hours at a constant voltage of $100 \mathrm{~V}$ and a constant temperature of $60^{\circ} \mathrm{C}$ in $1 \times \mathrm{TAE}$ buffer. After electrophoresis, the gel was stained for 30 minutes with 1:10000 dilution SYBR ${ }^{\mathrm{TM}}$ Green I nucleic acid gel stain (Invitrogen, Shanghai, China). The stained gel was immediately photographed under UV light with the Gel Doc XR+gel imaging system and digitized with Quantity One 
(version 4.4.0) software (Bio-Rad Laboratories, Hercules, CA, USA).

Eleven dominant bands were carefully excised from the DGGE gel and DNA was eluted by incubating each band in $40 \mu \mathrm{l}$ sterilized distilled MilliQ water overnight at $4^{\circ} \mathrm{C}$. Five microlitres of eluted DNA was used as a template for PCR amplification, using the same primers (341f/907r) and thermocycling programmes as described above. PCR products were cloned using the pEASYTM_T3 Cloning Kit (TransGen Biotech, Beijing, China) according to the manufacturer's recommendations, and transformed into trans1-T1 phage-resistant chemically competent E. coli cells (TransGen). Transformed colonies were screened for inserts of the correct size by PCR amplification with the specific primers M13F (TGT AAA ACG ACG GCC AGT) and M13R (TCA CAC AGG AA ACA GCT ATG AC). Sequencing of correct colonies (five replicate colonies for each band) was carried out with vector primer set M13F/M13R (Invitrogen, Shanghai, China). Vector sequences were removed by using DNASTAR Lasergene 7.1. The gene sequences of the DGGE bands were subjected to taxonomic assignments with reference sequences using Blastn (http://ncbi.nlm.nih.gov/blast). Phylogenetic analysis was performed using a neighbour-joining algorithm and distance calculation by MEGA4. Sequences that were $97 \%$ or more identical were considered as a unique operational taxonomic unit (OTU). All the sequences determined in this study were deposited in the GenBank database and have been assigned accession numbers KF186478 to KF186493.

\section{Statistical analysis}

All statistical tests were performed using SPSS software (version 14.0). Significant differences between means $(n=3)$ were determined using one-way ANOVA followed by the least significant difference test (LSD) at a level of $P<0.05$. Exponential regression analysis was conducted to relate DHA, SIR and $\mathrm{C}_{\text {mic }}$ to the quantity of electrons present within 48 hours.

The quantity of electrons, $Q$ (coulomb, C), produced was evaluated with the following formula:

$$
\begin{gathered}
Q=\sum_{\mathrm{n}=1}^{m} \frac{\left(I_{\mathrm{n}}+I_{\mathrm{n}+1}\right)}{2} \times 600, \\
I=U / R,
\end{gathered}
$$

where $U$ is the voltage (V), $I$ is the current (A), $R$ is the external loading $1000 \Omega, \mathrm{n}$ is the number of data recorded by a data acquisition module with a time interval of $600 \mathrm{~s}$, and $\mathrm{m}$ is the total number of voltage data within 48 hours.

\section{Results}

The response of $M F C$ voltage to $C u$ exposure

Plots of MFC voltage against operation time are depicted in Figure 2. It took approximately 8 days for MFCs without glucose

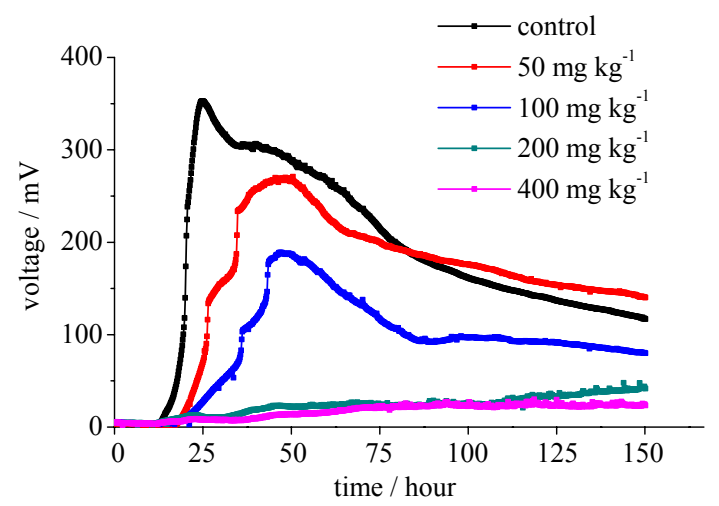

Figure 2 The voltage of MFCs $(n=3)$ with $\mathrm{Cu}$-spiked soil and control soil (without $\mathrm{Cu}$ addition). Data were collected every 10 minutes.

to reach 'start-up' and another 3 days to reach a peak voltage of $52 \mathrm{mV}$ (data not shown). Glucose addition accelerated the start-up and increased the peak voltage. For the control MFC with 5\% glucose, start-up occurred after 15 hours of operation and reached a peak voltage $(354 \mathrm{mV})$ after 25 hours of operation (Table 1). The copper additions at 50 and $100 \mathrm{mg} \mathrm{kg}^{-1}$ delayed the start-up, reduced the peak voltage and decreased the quantity of electrons produced significantly $(P<0.05)$. The MFC amended with 200 and $400 \mathrm{mg} \mathrm{kg}^{-1} \mathrm{Cu}^{2+}$ did not show a peak voltage; instead, the voltage of these treatments increased throughout the operation time. The MFC with fumigated soil had voltage below $1 \mathrm{mV}$ during the 150 hours of operation, indicating that the electrical power was produced by soil microorganisms.

Values of DHA, SIR and $\mathrm{C}_{\text {mic }}$ decreased significantly with increasing $\mathrm{Cu}^{2+}$ concentrations (Table 1) and were significantly correlated with the quantity of electrons produced within 48 hours, as indicated by an exponential regression (Figure 3). The transition from a steep to a flat slope of the exponential curve occurred with the decreasing $\mathrm{Cu}^{2+}$ concentration and greater numbers of electrons produced.

\section{Electrochemical activity}

The electrochemical activity of the soil solution recovered from anode chambers was determined with cyclic voltammetry (Figure 4). The fumigation treatment did not show any electrochemical activity. With the increase of $\mathrm{Cu}^{2+}$ concentration, the reduction peaks at around $-550 \mathrm{mV}$ became less negative. A pair of symmetric oxidation and reduction peaks at around -50 and $50 \mathrm{mV}$ were from $\mathrm{Cu}^{2+}$.

\section{Sequencing and phylogenetic analysis of the DGGE pattern}

The DGGE profiles of the bacterial 16S rRNA gene showed three distinct bands 4, 10 and 11, which were dominant in the anode samples rather than in the soil samples (Figure 5). Bands 4 and 11 were mainly detected in the $400 \mathrm{mg} \mathrm{kg}^{-1} \mathrm{Cu}^{2+}$ treatment while band 10 was mainly in the control treatment. The other bands 
Table 1 Mean and standard error (in parentheses) of quantity of electrons and peak voltage for microbial fuel cells amended with 5\% glucose, and summary of the analyses of variance

\begin{tabular}{|c|c|c|c|c|c|}
\hline 50 & $11.7(2.60)$ & $271(12.1)$ & $52.8(3.1)$ & $3.85(0.08)$ & $280(25.7)$ \\
\hline 100 & $7.7(2.15)$ & $189(5.9)$ & $43.6(2.9)$ & $3.15(0.05)$ & $217(12.0)$ \\
\hline 200 & $2.0(0.20)$ & - & $29.2(6.9)$ & $2.89(0.16)$ & 195 (11.9) \\
\hline $\mathrm{LSD}_{0.05}$ & 9.7 & 75.6 & 12.9 & 0.38 & 52.8 \\
\hline \multicolumn{6}{|l|}{ ANOVA results } \\
\hline Between treatments sum of squares & 1954.2 & 40180.2 & 9464.7 & 5.70 & 18731.0 \\
\hline Within treatments sum of squares & 282.7 & 10364.8 & 505.7 & 0.44 & 8439.2 \\
\hline Between treatments mean squares & 488.6 & 20090.1 & 2366.2 & 1.43 & 4682.8 \\
\hline Within treatments mean squares & 28.3 & 1727.5 & 50.6 & 0.04 & 843.9 \\
\hline
\end{tabular}

$\mathrm{LSD}_{0.05}$, least significant difference at $P<0.05$.

were largely shared between the anode and soil. Unlike many other bands, the intensity of band 6 did not decrease with increasing $\mathrm{Cu}^{2+}$ amount. The phylogenetic tree for $16 \mathrm{~S}$ rRNA gene sequences (Figure 6) from the anode samples only clustered bands 4 and 11 with Firmicutes and Bacillus, respectively. Band 10 was clustered with Acetobacteraceae and Bacillaceae. Bands 1, 2, 3, 5 and 6 were assigned to Clostridium. Bands 7, 8 and 9 were assigned to Sporolactobacillus.

\section{Discussion}

\section{The electrical signals from soil MFCs}

In MFCs, the electrogenic bacteria require time to enrich the anode to start-up and to produce power (Borole et al., 2010). The addition of easy-to-degrade carbon sources, such as glucose and acetate, accelerates the start-up of MFCs and improves power output (Deng et al., 2012). In our study, soil was mixed with $5 \%$ glucose $(w / w)$ to accelerate start-up effectively and improve voltage. We noted that peak voltage did not increase and start-up was not accelerated with the addition of more glucose $(8 \%, w / w)$ (data not shown). This could be because the current was saturated with $5 \%$ added glucose (Lee et al., 2008), although we cannot discard the possibility that the organic acids produced from the fermentation of excess glucose inhibited microbial activity (Sundberg \& Jonsson, 2005).

Cyclic voltammetry was used to identify the electrochemical activity of soil in the anode chamber in response to $\mathrm{Cu}^{2+}$ addition. The electrochemical activity decreased with increasing soil copper concentrations and was absent in the sterilized soil. This result indicated that increasing soil $\mathrm{Cu}^{2+}$ concentrations had a negative effect on the redox activity of the anode system, and that the measured electrochemical activity was related to soil microbial activity, either by electrogenic bacterial growth or by the presence of electrochemically active metabolic products.
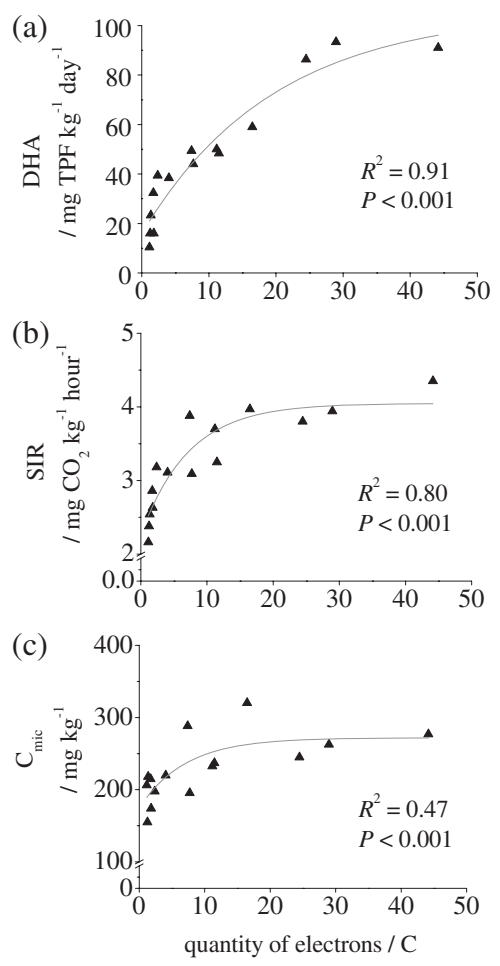

Figure 3 (a) Exponential regressions $(n=15)$ of dehydrogenase activity (DHA), (b) substrate-induced respiration (SIR) and (c) microbial biomass carbon $\left(\mathrm{C}_{\mathrm{mic}}\right)$ to the quantity of electrons produced within 48 hours of MFCs operation. The quantity of electrons produced is expressed in coulombs (C).

\section{The reliability of the MFC-based method}

The quantity of electrons produced within 48 hours decreased significantly with increasing soil $\mathrm{Cu}^{2+}$ concentrations. This result demonstrates the potential use for MFCs in assessing heavy metal 

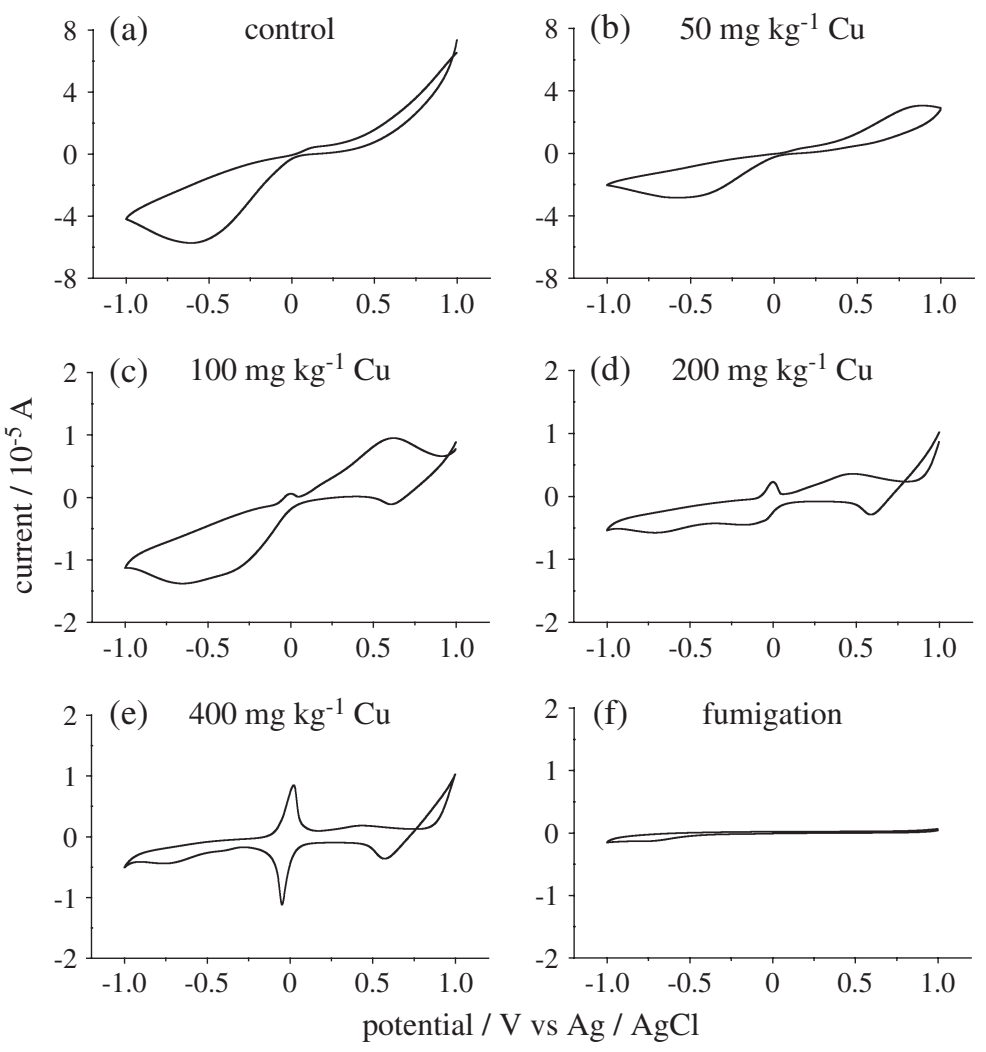

Figure 4 Cyclic voltammograms of soil solution from the MFC anode chamber with 50, 100, 200 and $400 \mathrm{mg} \mathrm{Cu}^{2+} \mathrm{kg}^{-1}$ (b-e). $(\mathrm{a}, \mathrm{f})$ The without-Cu control and fumigation treatment were set as references.

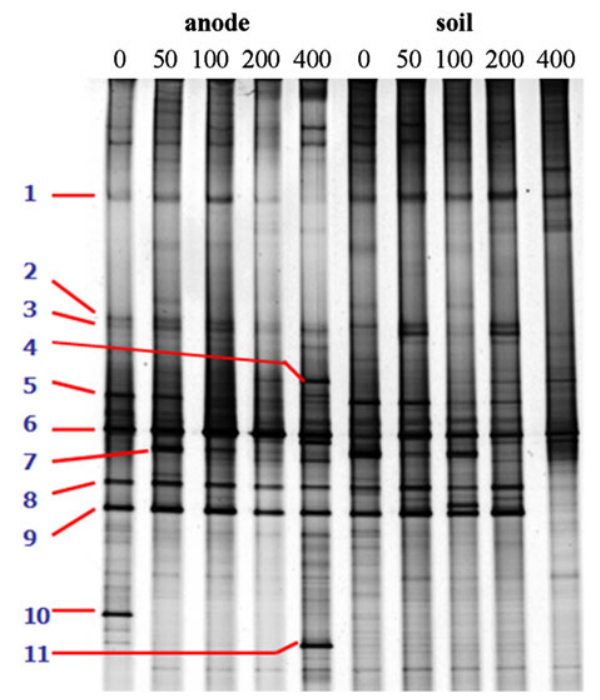

Figure 5 DGGE profiles of 16S rRNA gene fragments from the anode surface and anode chamber soil under different $\mathrm{Cu}^{2+}$ concentrations. The numbers $0-400$ denote $\mathrm{Cu}^{2+}$ concentrations of 0 (control), 50, 100, 200 and $400 \mathrm{mg} \mathrm{kg}^{-1}$. The numbers $1-11$ represent the dominant DGGE bands, which were excised for sequencing and phylogenetic analysis.

toxicity in soil microorganisms. To confirm the agreement of the MFC-based method with traditional methods, SIR, DHA and $\mathrm{C}_{\text {mic }}$ were also studied. Values from DHA provide one of the most sensitive indicators for soil microbial activity (Goyal et al., 2008).
The value of SIR largely depends on the metabolically active component of microbial biomass and is thus an indicator of the viable microbial community activity (Deng et al., 2009). The $\mathrm{C}_{\mathrm{mic}}$ is a measurement of the abundance of living microorganisms. Results of our study indicated that SIR, DHA and $\mathrm{C}_{\text {mic }}$ decreased with increasing amount of $\mathrm{Cu}^{2+}$, which is consistent with a large number of previous studies. Large concentrations of heavy metals can adversely affect soil microorganisms, inhibiting enzyme activities and thereby reducing overall microbial activity. However, $\mathrm{C}_{\text {mic }}$ measurements include active, inhibited and dormant cells: therefore it could be less sensitive to stress than DHA and SIR (Guo et al., 2013). The exponential regressions used to fit DHA, $\mathrm{C}_{\text {mic }}$ and SIR in relation to coulombs measured suggest that the quantity of electrons produced decreased to a greater extent than did SIR and $\mathrm{C}_{\text {mic }}$ in control and $50 \mathrm{mg} \mathrm{kg}^{-1} \mathrm{Cu}^{2+}$. Exocellular electron transfer by electrogenic bacteria is carried out by membrane-bound electron transport proteins, such as c-type cytochromes (Logan, 2009). In contrast, bacterial metabolic activities are controlled largely by endoenzymes. Copper toxicity is mitigated by a series of internal cellular mechanisms (Silver \& Phung, 1996). In addition, as a specific function, electrogenic activity is guaranteed by less redundant metabolic pathways or species than general functions of SIR or $\mathrm{C}_{\text {mic }}$. Therefore, the measure of power generation was more sensitive to the smaller $\mathrm{Cu}^{2+}$ concentrations than either SIR or $\mathrm{C}_{\text {mic }}$. These results indicate that electrical signals may be useful in identifying the presence of small amounts of pollution in soil. We also suggest that soil be tested under controlled conditions 


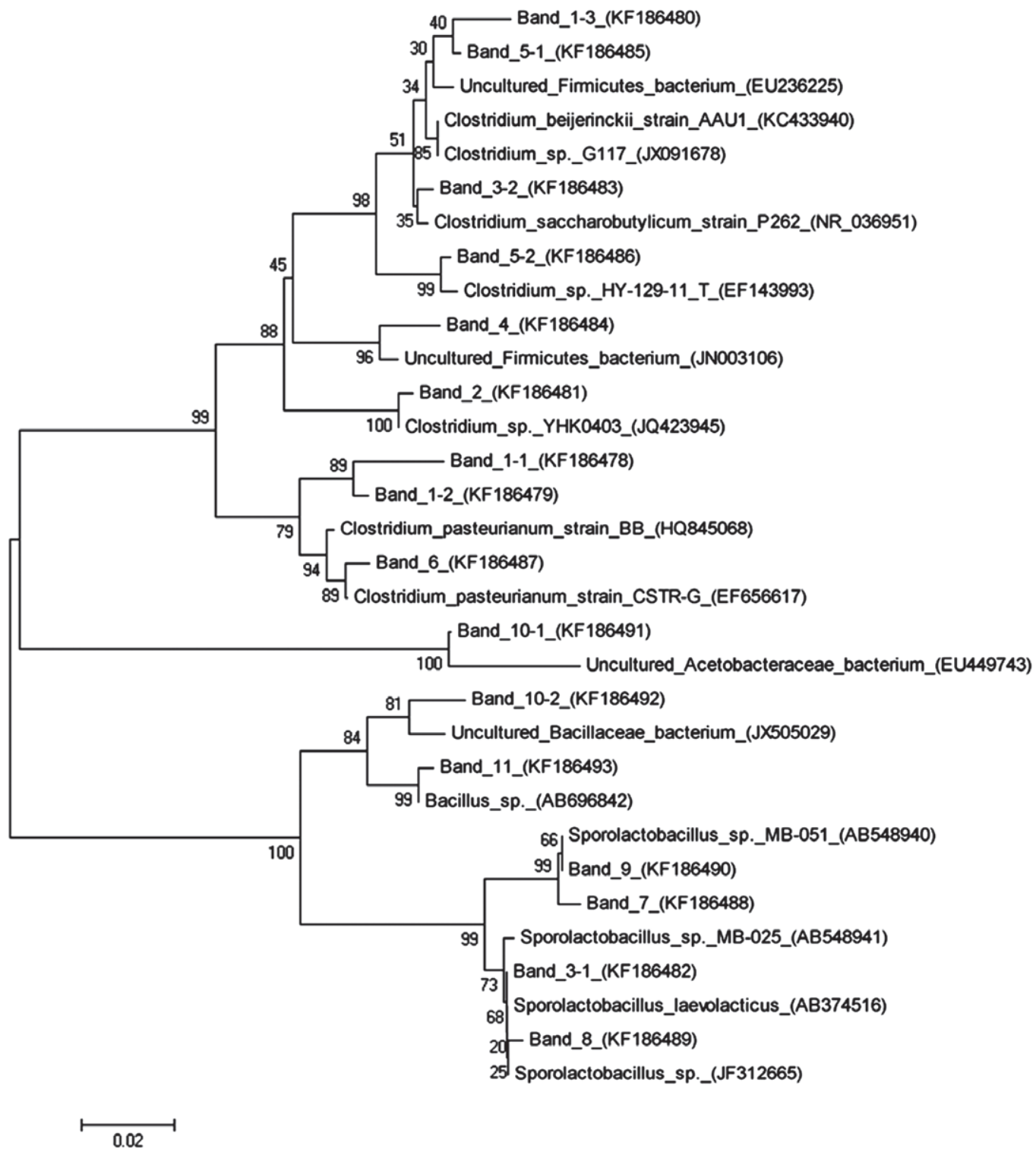

Figure 6 Phylogenetic relationships between DGGE band sequences and 16S rRNA gene sequences retrieved from the GenBank database. The tree represents the alignment of a 525-bp region in 16S rRNA gene sequences. Genebank accession numbers are KF186478 to KF186493. The scale bar represents dissimilarity among sequences.

with constant temperature to prevent power generation fluctuations (Deng et al., 2014).

\section{The DNA-based analysis of anodic bacteria}

Phylogenetic analysis of the $16 \mathrm{~S}$ rRNA gene from the anode demonstrated the composition of anodic bacteria. Three bands distinct to the anode samples were assigned to Firmicutes, Bacillus, Acetobacteraceae and Bacillacea. Previous research has assigned electrogenic bacteria to the Proteobacteria and Firmicutes phyla (Kim et al., 2008) and within the Firmicutes, Acetobacterium, Bacillus, Clostridium, Corynebacterium, Lactobacillus, Lactococcus and Streptococcus were identified. A number of anodic bacteria have been isolated and their electrogenic activities confirmed (Park et al., 2001; Chung \& Okabe, 2009; Xing et al., 2010; Wu et al., 2013). Bacillus sp. transfer electrons to the anode mainly through soluble redox-active mediators (Nimje et al., 2009). In a study of forest soil, Kappler et al. (2004) found that iron (Fe(III)/Fe(II)) and humic acids acted as electron mediators. Acetobacterium plays a role in current generation by producing acetate, one of the most favourable substrate for electrogenic bacteria, through glucose fermentation or homo-acetogenic processes (Ziv-El et al., 2012). In addition to the three distinct bands from the anode samples, bands shared by both anode and soil were identified and assigned to Clostridium and Sporolactobacillus. Sporolactobacillus ferment glucose 
and produce D lactate (Wang et al., 2011), but an electrogenic activity has not been reported. Clostridium organisms are electrogenically active. The Firmicutes, Clostridium sp. and Bacillus sp. represented by bands 4, 6 and 11, respectively, are possibly $\mathrm{Cu}$-resistant. The Bacillus sp. dominate bacterial communities in heavy metal-polluted soils (Ellis et al., 2003). However, in spite of the presence of Firmicutes, Bacillus and Clostridium in 200 and $400 \mathrm{mg} \mathrm{kg}^{-1} \mathrm{Cu}^{2+}$-amended soil, the measured voltage was very small with a slow start-up. The $\mathrm{Cu}^{2+}$ exposure severely inhibited the electrogenic activity and the start-up of voltage probably resulted from adsorption of $\mathrm{Cu}^{2+}$ on soil, and resilience of microbial activity (Deng et al., 2009).

\section{Conclusions}

Our study is the first to use the electrical signals of soil-based MFCs to monitor the effects of $\mathrm{Cu}^{2+}$ on soil microorganisms as far as we are aware. We conclude that the electrical signals of MFCs with glucose-amended soil can be used to evaluate the ecotoxicity of soil pollutants. The electrical signals produced are very sensitive to small stresses. Nevertheless, there are several limitations that should be overcome to facilitate application, including (i) minimizing the volume of MFC reactors and the amount of soil for a test, (ii) using oxygen as a sustainable electron acceptor rather than ferricyanide, and (iii) reducing the cost and improving the performance of electrodes and the cation exchange membrane. Further research is needed to validate the technique and to assess the reliability of the method with different stressors and with different soil types.

\section{Acknowledgements}

This study was supported by the Natural Science Foundation of China (41301260), the National Key Technology R\&D Program (2013BAD11B01) and the Academic Priority Development Program of Jiangsu Higher Education Institutions (164320H101). We thank Professor Luis Sayavedra-Soto from Oregon State University (USA) for editorial comments.

\section{References}

Bond, D.R. \& Lovley, D.R. 2003. Electricity production by Geobacter sulfurreducens attached to electrodes. Applied \& Environmental Microbiology, 69, 1548-1555.

Borole, A.P., Aaron, D., Hamilton, C.Y. \& Tsouris, C. 2010. Understanding long-term changes in microbial fuel cell performance using electrochemical impedance spectroscopy. Environmental Science \& Technology, 44, 2740-2745.

Casida, L.E., Klein, D.A. \& Santoro, T. 1964. Soil dehydrogenase activity. Soil Science, 98, 371-376.

Chung, K. \& Okabe, S. 2009. Continuous power generation and microbial community structure of the anode biofilms in a three-stage microbial fuel cell system. Applied Microbiology \& Biotechnology, 83, 965-977.

da Rosa, A.C. 2011. Diversity and function of the microbial community on anodes of sediment microbial fuel cells fueled by root exudates. $\mathrm{PhD}$ thesis, University of Marburg, Marburg.
Dávila, D., Esquivel, J.P., Sabaté, N. \& Mas, J. 2010. Silicon-based microfabricated microbial fuel cell toxicity sensor. Biosensors \& Bioelectronics, 26, 2426-2430.

Deng, H., Li, X.F., Cheng, W.D. \& Zhu, Y.G. 2009. Resistance and resilience of $\mathrm{Cu}$-polluted soil after $\mathrm{Cu}$ perturbation, tested by a wide range of soil microbial parameters. Federation of European Microbiological Societies Microbiology Ecology, 70, 293-304.

Deng, H., Chen, Z. \& Zhao, F. 2012. Energy from plants and microorganisms--progress in plant-microbial fuel cells. Chemistry \& Sustainability, 5, 1006-1011.

Deng, H., Wu, Y.C., Zhang, F., Huang, Z.C., Chen, Z., Xu, H.J. et al. 2014. Factors affecting the performance of single-chamber soil microbial fuel cells for power generation. Pedosphere, 24, 330-338.

Di Lorenzo, M., Curtis, T.P., Head, I.M. \& Scott, K. 2009. A single-chamber microbial fuel cell as a biosensor for wastewaters. Water Research, $\mathbf{4 3}$, 3145-3154.

Ellis, R.J., Morgan, P., Weightman, A.J. \& Fry, J.C. 2003. Cultivation -dependent and -independent approaches for determining bacterial diversity in heavy-metal-contaminated soil. Applied \& Environmental Microbiology, 69, 3223-3230.

Gee, G.W. \& Bauder, J.W. 1986. Particle-size analysis. In: Methods of Soil Analysis, Part 1, Physical and Mineralogical Methods (ed A. Clute), pp. 383-411. American Society of Agronomy \& Soil Science Society of America, Madison, WI.

Goyal, S., Walia, M., Gera, R., Kapoor, K.K. \& Kundu, B.S. 2008. Impact of sewage sludge application on soil microbial biomass, microbial processes and plant growth- a review. Review of Agricultural Economics, 29, 1-10.

Guo, G.X., Deng, H., Qiao, M., Yao, H.Y. \& Zhu, Y.G. 2013. Effect of long-term wastewater irrigation on potential denitrification and denitrifying communities in soil at the watershed scale. Environmental Science \& Technology, 47, 3105-3113.

He, Z., Kan, J.J., Wang, Y.B., Huang, Y.L., Mansfeld, F. \& Nealson, K.H. 2009. Electricity production coupled to ammonium in a microbial fuel cell. Environmental Science \& Technology, 43, 3391-3397.

Ishii, S., Shimoyama, T., Hotta, Y. \& Watanabe, K. 2008. Characterization of a filamentous biofilm community established in a cellulose-fed microbial fuel cell. BMC Microbiology, 8, 1-12.

IUSS Working Group WRB 2007. World Reference Base for Soil Resources 2006, first update 2007. World Soil Resources Reports No. 103, FAO, Rome.

Kaku, N., Yonezawa, N., Kodama, Y. \& Watanabe, K. 2008. Plant/microbe cooperation for electricity generation in a rice paddy field. Applied Microbiology \& Biotechnology, 79, 43-49.

Kappler, A., Benz, M., Schink, B. \& Brune, A. 2004. Electron shuttling via humic acids in microbial iron(III) reduction in a freshwater sediment. Federation of European Microbiological Societies Microbiology Ecology, 47, 85-92.

Kim, I.S., Chae, K.J., Choi, M.J. \& Verstraete, W. 2008. Microbial fuel cells: recent advances, bacterial communities and application beyond electricity generation. Environmental Engineering Research, 13, 51-65.

Kim, N.J., Choi, Y.J., Jung, S.H. \& Kim, S.Y. 2000. Effect of initial carbon sources on the performance of microbial fuel cells containing proteus vulgaris. Biotechnology \& Bioengineering, 70, 109-114.

Lee, H.S., Parameswaran, P., Kato-Marcus, A., Torres, C.I. \& Rittmann, B.E. 2008. Evaluation of energy-conversion efficiencies in microbial fuel cells (MFCs) utilizing fermentable and non-fermentable substrates. Water Research, 42, 1501-1510. 
Lipson, D.A., Schmidt, S.K. \& Monson, R.K. 1999. Links between microbial population dynamics and nitrogen availability in an alpine ecosystem. Ecology, 80, 1623-1631.

Logan, B.E. 2009. Exoelectrogenic bacteria that power microbial fuel cells. Nature Reviews Microbiology, 7, 375-381.

Muyzer, G., de Waal, E.C. \& Uitterlinden, A.G. 1993. Profiling of complex microbial populations by denaturing gradient gel electrophoresis analysis of polymerase chain reaction-amplified genes coding for $16 \mathrm{~S}$ rRNA. Applied \& Environmental Microbiology, 59, 695-700.

Nimje, V.R., Chen, C.Y., Chen, C.C., Jean, J.S., Reddy, A.S., Fan, C.W. et al. 2009. Stable and high energy generation by a strain of Bacillus subtilis in a microbial fuel cell. Journal of Power Sources, 190, 258-263.

Park, H.S., Kim, B.H., Kim, H.S., Kim, H.J., Kim, J.T., Kim, M. et al. 2001. A novel electrochemically active and Fe(III)-reducing bacterium phylogenetically related to Clostridium butyricum isolated from a microbial fuel cell. Anaerobe, 7, 297-306.

Ringelberg, D.B., Foley, K.L. \& Reynolds, C.M. 2011. Electrogenic capacity and community composition of anodic biofilms in soil-based bioelectrochemical systems. Applied Microbiology \& Biotechnology, 90, $1805-1815$.

Shen, Y.J., Lefebvre, O., Tan, Z. \& Ng, H.Y. 2012. Microbial fuel-cell-based toxicity sensor for fast monitoring of acidic toxicity. Water Science Technology, 65, 1223-1228.

Shen, Y.J., Wang, M., Chang, I.S. \& Ng, H.Y. 2013. Effect of shear rate on the response of microbial fuel cell toxicity sensor to $\mathrm{Cu}$ (II). Bioresource Technology, 136, 707-710.

Silver, S. \& Phung, L.T. 1996. Bacterial heavy metal resistance: new surprises. Annual Review of Microbiology, 50, 753-789.

Stein, N.E., Hamelers, H.V. \& Cees, N.J. 2010. Buisman stabilizing the baseline current of a microbial fuel cell-based biosensor through overpotential control under non-toxic conditions. Bioelectrochemistry, 78, 87-91.
Stein, N.E., Keesman, K.J., Hamelers, H.V.M. \& van Straten, G. 2011. Kinetic models for detection of toxicity in a microbial fuel cell based biosensor. Biosensors \& Bioelectronics, 26, 3115-3120.

Sundberg, C. \& Jonsson, H. 2005. Process inhibition due to organic acids in fed-batch composting of food waste influence of starting culture. Biodegradation, 16, 205-213.

Vance, E.D., Brookes, P.C. \& Jenkinson, D.S. 1987. An extraction method for measuring soil microbial biomass. Soil Biology \& Biochemistry, 19, $703-707$.

Wang, L.M., Zhao, B., Li, F.S., Xu, K., Ma, C.Q., Tao, F. et al. 2011. Highly efficient production of D-lactate by Sporolactobacillus sp. CASD with simultaneous enzymatic hydrolysis of peanut meal. Applied Microbiology \& Biotechnology, 89, 1009-1017.

Wang, Y.P., Shi, J.Y., Wang, H., Lin, Q., Chen, X.C. \& Chen, Y.X. 2007. The influence of soil heavy metals pollution on soil microbial biomass, enzyme activity, and community composition near a copper smelter. Ecotoxicology \& Environmental Safety, 67, 75-81.

Wolf, D.C., Dao, T.H., Scott, H.D. \& Lavy, T.L. 1989. Influence of sterilization methods on selected soil microbiological, physical, and chemical properties. Journal of Environmental Quality, 18, 39-44.

Wu, C.Y., Zhuang, L., Zhou, S.G., Yuan, Y., Yuan, T. \& Li, F.B. 2013. Humic substance-mediated reduction of iron(III) oxides and degradation of 2,4-D by an alkaliphilic bacterium, Corynebacterium humireducens MFC-5. Microbial Biotechnology, 6, 141-149.

Xing, D.F., Cheng, S.A., Logan, B.E. \& Regan, J.M. 2010. Isolation of the exoelectrogenic denitrifying bacterium Comamonas denitrificans based on dilution to extinction. Applied Microbiology \& Biotechnology, 85, 1575-1587.

Ziv-El, M., Popat, S.C., Parameswaran, P., Kang, D.W., Polasko, A., Halden, R.U. et al. 2012. Using electron balances and molecular techniques to assess trichoroethene-induced shifts to a dechlorinating microbial community. Biotechnology \& Bioengineering, 109, 2230-2239. 